\title{
PENGELOLAAN RUMAH TANGGA NELAYAN DITINJAU DARI PERSEPSI JENDER (Studi Kasus di Kelurahan Pasie Nan Tigo Kota Padang).
}

\author{
Mursidin, Hikmah dan Zahri Nasution'
}

\begin{abstract}
ABSTRAK
Penelitian ini dilakukan di Kelurahan Pasie Nan Tigo, Kecamatan Koto Tangah, Kota Padang. Penelitian bertujuan untuk mendapatkan informasi tentang peranan keluarga dalam pengelolaan rumah tangga nelayan ditinjau dari persepsi jender. Metode yang digunakan adalah metode survey yang bersifat deskriftip. Data yang digunakan dalam penelitian ini adalah data primer dan data sekunder. Data di analisis menggunakan metode Harvard dan dibahas secara deskriptif. Hasil penelitian menunjukkan bahwa pada analisis kesetaraan jender masih adanya ketimpangan jender yang mewarnai pola kerja masyarakat nelayan setempat yakni adanya beban kerja, dimana istri memiliki peran ganda yaitu sebagai penanggung jawab dalam urusan rumah tangga dan juga membantu suami sebagai pencari nafkah. Persepsi jender yang paling banyak dianut oleh suami dan istri dalam keluarga nelayan pada masyarakat tersebut adalah istri dan suami menyadari bahwa perbedaan jenis kelamin tidak harus dipertentangkan dalam menghidupi keluarga, tetapi justru bersifat saling mendukung dan melengkapi. Sedangkan tugas berdasarkan jender yang paling banyak dianut baik oleh suami dan istri dalam keluarga nelayan pada masyarakat tersebut adalah tugas utama istri mengurus rumah tangga; tetapi boleh membantu tugas suami dalam mencari nafkah keluarga sedangkan tanggung jawab mencari nafkah utama tetap tugas suami.
\end{abstract}

\section{Kata Kunci : Pengelolaan Rumah Tangga Nelayan, Persepsi Jender.}

Abstract : Gender Perception of Fisheries Household Management (Case Study in Village of the Pasie Nan Tigo, Padang District). By: Mursidin, Hikmah And Zahri Nasution.

This research was conducted at the village of Pasie Nan Tigo, sub district of the Koto Tangah Padang, The research was aimed to analyze the role of family's member in of fisheries household management in gender perception point of view. Survey method was used in this research to collect the Primary and secondary data. Harvard method was used to analyze the data and the results were also briefly discussed descriptively. The results of the study showed that gender equity was unbalanced between wife and husband. That wives play a double roles; as a housewife and help their husband to generate income. In the perception of gender equity, wife has to be a housewife and help husband to get money, but husband hasa main responsibility to earn money for the household.

\section{Keywords: Management In Family Fisheries, Perception of Gender.}

\section{PENDAHULUAN}

Masyarakat nelayan khususnya nelayan kecil memiliki karakteristik sosial ekonomi yang berbeda dengan masyarakat industri atau masyarakat lainnya. Perbedaan ini disebabkan oleh keterkaitan yang erat terhadap karakteristik ekonomi, ketersediaan sarana dan prasarana ekonomi, sosial maupun budaya. Kondisi sosial ekonomi masyarakat nelayan dapat dikatakan memprihatinkan. Hal ini antara lain terlihat dengan rendahnya tingkat pendidikan, produktivitas dan pendapatan masyarakat nelayan, terutama nelayan buruh atau Anak Buah kapal (ABK) (Nasution et al., 2004).

Data terakhir Departemen Kelautan dan Perikanan (2005) menunjukkan indeks kemiskinan (Proverty Headcount Index, PHI) masyarakat di desa pesisir yang didominasi oleh nelayan masih sebesar 0,28. Besaran nilai indeks ini menunjukkan bahwa hampir $30 \%$ populasi penduduk yang hidup di dalam keluarga yang tinggal di wilayah pesisir (nelayan) masih memiliki pengeluaran konsumsi per kapita dibawah garis

\footnotetext{
1 Peneliti pada Balai Besar Riset Sosial Ekonomi Kelautan dan Perikanan 
kemiskinan. Lebih lanjut nilai PHI masyarakat wilayah ini juga relatif masih lebih tinggi dibandingkan dengan $\mathrm{PHI}$ rata-rata masyarakat di Indonesia sebesar 0,18 (Departemen Kelautan dan Perikanan, 2006). Kelompok masyarakat nelayan ini mencapai 3,2 juta orang yang mendiami 3.632 desa nelayan penangkapan (BPS, 2003). Kondisi ini tentunya ironis jika dibandingkan dengan banyaknya upaya pembangunan yang telah dilakukan oleh pemerintah (BBRSEKP, 2005).

Menurut Kusnadi dalam Ahmad (2005) kemiskinan dan tekanan-tekanan sosial ekonomi yang dihadapi oleh rumahtangga nelayan, berakar pada faktor-faktor kompleks yang saling terkait, faktor-faktor tersebut dapat diklasifikasikan ke dalam faktor alamiah dan faktor non alamiah. Faktor alamiah antara lain yang berhubungan dengan musim ikan dan musim paceklik, sedangkan faktor non alamiah yang berhubungan dengan teknologi penangkapan (alat tangkap yang dimiliki).

Musim penangkapan ikan di Kelurahan Pasie Nan Tigo, Kecamatan Koto Tangah, Kota Padang (Sumatera Barat) tidak berlangsung sepanjang tahun karena terkendala oleh musim ombak dan angin kencang, waktu efektif untuk menghasilkan produksi tangkapan hanya 4(empat) bulan (Oktober sampai Januari), pada waktu itu nelayan memperoleh penghasilan yang lebih baik. Pada musim paceklik (musim ombak dan angin kencang) penghasilan nelayan akan mulai berkurang yang berlangsung selama 8(delapan) bulan, penghasilan nelayan berkurang karena jarak tempuh nelayan tidak terlalu jauh karena keterbatasan alat tangkap yang dimiliki bahkan lebih banyak waktu tidak melaut (didarat) karena hasil yang diperoleh tidak bisa menutupi biaya operasional yang dikeluarkan. Untuk menambah penghasilan keluarga bagaimana peranan nelayan (suami) dan istri nelayan dalam menghidupi keluarga apakah terjadi ketidak setaraan gender, baik dalam kegiatan produktip (publik) maupupun kegiatan reproduktip (domestik).

\section{METODOLOGI}

\section{Lokasi Penelitian dan Waktu Penelitian}

Penelitian ini dilakukan di Kecamatan Koto Tangah Desa Pasie Nan Tigo, Kota Padang pada tahun 2007. Pemilihan lokasi penelitian secara sengaja dengan pertimbangan bahwa kawasan tersebut merupakan wilayah pesisir pantai dengan jumlah nelayan dan produksi nelayan paling banyak, termasuk pengolahan ikan yang dilakukan oleh istri nelayan.

\section{Metode Penelitian}

Penelitian ini berupa studi kasus pada rumahtangga nelayan di desa Pasie Nan Tigo, Kecamatan Koto Tangah Kota Padang dengan penelitian penjelasan (explanatory research) dimana dalam pelaksanaannya dilakukan dengan metode survey yang bersifat deskriptif yakni berusaha menggambarkan secara tepat sifat-sifat suatu individu, keadaan, gejala suatu kelompok atau lembaga tertentu untuk menentukan penyebarannya dalam masyarakat serta menerangkan hubungan antara fenomena yang diamati. Selain itu juga dilengkapi dengan metode wawancara mendalam (indepth interview) dengan menggunakan pedoman wawancara yang telah disiapkan.

\section{Jenis Data}

Data yang digunakan dalam penelitian ini adalah data primer dan data sekunder. Data primer dikumpulkan secara langsung dengan teknik survey melalui wawancara dengan responden bedasarkan pada kuesioner yang telah dibuat dan wawancara mendalam (indepth interview). Disamping wawancara dilakukan pengamatan langsung dilapangan untuk melengkapi data primer yang dibutuhkan. Adapun data primer yang dikumpulkan meliputi: karakteristik individu, umur, jumlah keluarga, pendidikan, jenis pekerjaan, pendapatan. Data yang diperoleh ditabulasikan dalam bentuk tabel dan dianalisis dengan metode Harvard. 
Analisis Harvard merupakan salah satu metode penelitian analsis gender. Metode ini mempunyai 3 komponen utama yaitu profil kegiatan, profil akses dan kontrol, dan analisis faktor yang mempengaruhi akses kontrol. Untuk mengetahui peranan wanita/pria dalam pengambilan keputusan dapat digunakan profil akses-kontrol (Purnamawati \& Lumangkun, 2000).

\section{HASIL DAN PEMBAHASAN}

\section{Profil Rumahtangga Nelayan di Kelurahan Pasie Nan Tigo \\ Profil Pribadi}

Status responden yang terdiri dari nelayan pemilik 11 Orang (36,67\%), juragan laut, nakhoda, juru mudi tidak ada, ABK sebanyak 19 orang (63,24\%). Sedangkan pekerjaan istri terdiri dari bakul ikan 6 orang $(20,00 \%)$, pedagang ikan olahan 4 orang $(13,33 \%)$, pengolah ikan 9 orang $(30,00 \%)$, dan lainnya (bikin kue, buka warung) sebanyak 7 orang (23,33\%) (Tabel 1). Dengan demikian terlihat bahwa hampir semua istri responden bekerja (26 orang) atau $86,67 \%$ dan yang tidak bekerja hanya 4 orang.

\section{Kelompok Umur Contoh}

Tabel 2 menunjukkan bahwa sebaran usia yang paling banyak adalah usia 46 - 54 tahun (sebanyak 18 orang) termasuk golongan tua, golongan sedang (35 -45 tahun) sebanyak 7 orang dan golongan muda hanya 2 orang. Sedangkan sebaran umur istri golongan sedang yang paling banyak (20 orang), golongan muda hanya 5 orang dan yang termasuk golongan tua juga 5 orang.

Dari Tabel 2 terlihat bahwa responden yang paling banyak (18 orang) termasuk golongan tua (46 - 54 tahun) tetapi masih produktif, dengan melihat sebaran umur tersebut bisa dikatakan bahwa rumahtangga nelayan di daerah ini sangat menggantungkan sumber pendapatan keluarga hanya dengan mengekstraksi perikanan laut.

\section{Tabel 1. Sebaran Status Responden Terkait Usaha Penangkapan di Kelurahan Pasie Nan Tigo Kota Padang.}

Table 1. Distribution Status of Respondent Related to Fisheries bussined in the Pasie Nan Tigo Village, Padang.

\begin{tabular}{|c|c|c|c|c|c|}
\hline \multirow[b]{2}{*}{ No } & \multirow[b]{2}{*}{$\begin{array}{l}\text { Status Responden/ } \\
\text { Respondent Status }\end{array}$} & \multicolumn{2}{|c|}{ Suami/Husband } & \multicolumn{2}{|c|}{ Istri/Wife } \\
\hline & & $\begin{array}{c}\text { Jumlah } \\
\text { Responden/ } \\
\text { Total } \\
\text { Respondent }\end{array}$ & $\begin{array}{l}\text { Persentase } \\
\text { Percentage } \\
\text { (\%) }\end{array}$ & $\begin{array}{c}\text { Jumlah } \\
\text { Responden/ } \\
\text { Total } \\
\text { Respondent }\end{array}$ & $\begin{array}{c}\text { Persentase/ } \\
\text { Percentage } \\
(\%)\end{array}$ \\
\hline 1. & $\begin{array}{l}\text { Nelayan pemilik kapal } \\
\text { (juragan darat)/ } \\
\text { Fisherman }\end{array}$ & 11 & 36,67 & - & - \\
\hline 2. & Juragan Laut/Owner & - & - & - & - \\
\hline 3. & ABK/Shipman & 19 & 63,34 & - & - \\
\hline 4. & Bakul ikan/Retailer & - & - & 6 & 20,00 \\
\hline 5. & $\begin{array}{l}\text { Pedagang ikan } \\
\text { olahan/Processed fish } \\
\text { retailer }\end{array}$ & - & - & 4 & 13,33 \\
\hline 6. & $\begin{array}{l}\text { Pengolah ikan/Fish } \\
\text { retailer }\end{array}$ & - & - & 9 & 30,00 \\
\hline 7. & $\begin{array}{l}\text { Lainnya (bikin kue, buka } \\
\text { warung)/other (in order } \\
\text { to cake,open small shop }\end{array}$ & - & - & 7 & 23,33 \\
\hline
\end{tabular}

Sumber : Data Primer Diolah, 2007/Source : Primary Data Processed, 2007. 
Tabel 2. Sebaran Umur Responden di Desa Pasie Nan Tigo Kota Padang.

Table 2. Age Distribution of Respondent in the Pasie Nan Tigo Village, Padang .

\begin{tabular}{llrrrr}
\hline No & $\begin{array}{c}\text { Golongan Umur/ } \\
\text { Level of Age }\end{array}$ & \multicolumn{2}{c}{$\begin{array}{c}\text { Responden Suami I } \\
\text { Husband Respondent }\end{array}$} & \multicolumn{2}{c}{$\begin{array}{c}\text { Responden Istri I } \\
\text { Wife Respondent }\end{array}$} \\
\cline { 3 - 6 } & $\begin{array}{c}\text { Jumlah } \\
\text { Orang/Total } \\
\text { Person }\end{array}$ & $\%$ & $\begin{array}{c}\text { Jumlah } \\
\text { Orang/Total } \\
\text { Person }\end{array}$ & $\%$ \\
\hline 1. & $15-24$ & 0 & 0,00 & 0 & 0,00 \\
2. & $25-34$ & 2 & 6,67 & 5 & 16,67 \\
3. & $35-45$ & 7 & 23,33 & 20 & 66,67 \\
4. & $46-54$ & 18 & 60,00 & 5 & 16,67 \\
5. & $>55$ & 3 & 10,00 & 0 & 0,00 \\
& Total & $\mathbf{3 0}$ & $\mathbf{1 0 0 , 0 0}$ & $\mathbf{3 0}$ & $\mathbf{1 0 0 , 0 0}$ \\
\hline
\end{tabular}

Sumber : Data Primer Diolah, 2007/Source : Primary Data Processed, 2007.

\section{Tingkat Pendidikan}

Pendidikan khususnya pendidikan formal, merupakan modal yang sangat berperan untuk mendapatkan kehidupan ekonomi lebih baik Pendidikan juga sangat mempengaruhi pola kehidupan setiap individu, baik cara berpikir dan bersikap.
Sebaran tingkat pendidikan dapat dilihat pada Tabel 3.

Sebaran tingkat pendidikan untuk responden nelayan sebahagian besar tidak tamat SD 15 orang $(50,00 \%)$, tamat SD 10 orang $(33,33 \%)$, tamat SMP 2 orang $(6,67 \%)$, tidak tamat SMA 3 orang $(10,00 \%)$.

Tabel 3. Tingkat Pendidikan Responden di Desa Pasie Nan Tigo, Kota Padang.

Table 3. Level of Education of Respondent in the Pasie Nan Tigo Village, Padang .

\begin{tabular}{|c|c|c|c|c|c|}
\hline \multirow[b]{2}{*}{ No } & \multirow[b]{2}{*}{ Kategori/Catagories } & \multicolumn{2}{|c|}{$\begin{array}{l}\text { Responden Suami/ } \\
\text { Husband Respondent }\end{array}$} & \multicolumn{2}{|c|}{$\begin{array}{l}\text { Responden Istri/ } \\
\text { Wife Respondent }\end{array}$} \\
\hline & & $\begin{array}{c}\text { Jumlah } \\
\text { Orang/Total } \\
\text { Person }\end{array}$ & $\%$ & $\begin{array}{c}\text { Jumlah } \\
\text { Orang/Total } \\
\text { Person }\end{array}$ & $\%$ \\
\hline 1. & Tidak sekolah/Uneducated & 0 & 0,00 & 0 & 0,00 \\
\hline 2. & $\begin{array}{l}\text { Tidak tamat SD/Elementary } \\
\text { School drop out }\end{array}$ & 15 & 50,00 & 10 & 33,34 \\
\hline 3. & $\begin{array}{l}\text { Tamat SD/Elementary School } \\
\text { graduated }\end{array}$ & 10 & 33,33 & 9 & 30,00 \\
\hline 4. & $\begin{array}{l}\text { Tidak Tamat SMP/ Junior High } \\
\text { School drop out }\end{array}$ & 0 & 0,00 & 4 & 13,34 \\
\hline 5. & $\begin{array}{l}\text { Tamat SMP/ Junior High School } \\
\text { graduated }\end{array}$ & 2 & 6,67 & 2 & 6,66 \\
\hline 6. & $\begin{array}{l}\text { Tidak Tamat SMA/ Senior High } \\
\text { School Drop Out }\end{array}$ & 3 & 10,0 & 2 & 16,66 \\
\hline 7. & $\begin{array}{l}\text { Tamat SMA/ Senior High School } \\
\text { graduated }\end{array}$ & 0 & 00,00 & 3 & 10,00 \\
\hline 8. & $\begin{array}{l}\text { Tidak Tamat PT/ Univercity drop } \\
\text { out }\end{array}$ & 0 & 0,00 & 0 & 0,00 \\
\hline 9. & $\begin{array}{l}\text { Tamat PT/ Univercity graduated } \\
\text { Jumlah/Total }\end{array}$ & $\begin{array}{r}0 \\
30\end{array}$ & $\begin{array}{r}0,00 \\
100.00\end{array}$ & $\begin{array}{r}0 \\
30\end{array}$ & $\begin{array}{r}0,00 \\
100.00\end{array}$ \\
\hline
\end{tabular}

Sumber : Data Primer Diolah, 2007/Source : Primary Data Processed, 2007. 
Sedangkan pendidikan istri tidak tamat SD 10 orang $(33,34 \%)$, tamat SD 9 orang $(30,00 \%)$, tidak tamat SMP 4 orang $(13,34 \%)$, tamat SMP 2 orang $(6,66 \%)$, tidak tamat SMA 2 orang $(6,66 \%)$, tamat SMA 3 orang $(10,00 \%)$.

\section{Tingkat Pendapatan}

Pendapatan nelayan berkisar antara Rp 600.000 (ABK) yang terendah dan yang tertinggi Rp 1.500.000 (nelayan pemilik). Pendapatan ABK kisarannya mulai Rp 600.000 sampai $\mathrm{Rp} 750.000$, Sedangkan pendapatan yang tertinggi adalah pengolah ikan sekitar Rp 2.000.000/bulan.

Apabila dilihat kondisi pendapatan yang tertinggi adalah pengolah (istri nelayan), wanita disini sangat berperan dalam menambah pendapatan keluarga (khsusnya di

Tabel4.Sebaran Tingkat Pendapatan Responden di Desa Pasie Nan Tigo Kota Padang.

Table 4. Income Level Distribution Respondent in the Pasie Nan Tigo Village, Padang.

\begin{tabular}{|c|c|c|c|c|}
\hline $\begin{array}{c}\text { Tingkat } \\
\text { Pendapatan } \\
\text { (Rp/Bulan)/ } \\
\text { Income Level } \\
\text { (Rp/Mounth) } \\
\mathrm{N}=30\end{array}$ & $\begin{array}{l}\text { Pendapatan } \\
\text { Suami } \\
\text { (Rp/Bulan)/ } \\
\text { Husband } \\
\text { Income } \\
\text { (Rp/Mounth) } \\
\mathrm{N}=30\end{array}$ & $\begin{array}{c}\text { Prosentase/ } \\
\text { Percentage } \\
(\%)\end{array}$ & $\begin{array}{c}\text { Pendapatan Istri } \\
\text { (Rp/Bulan) I } \\
\text { Wife Income } \\
\text { Rendah/Low } \\
\mathrm{N}=30\end{array}$ & $\begin{array}{c}\text { Prosentase/ } \\
\text { Percentage } \\
\text { (\%) }\end{array}$ \\
\hline Rendah/Low & 5 & 16,67 & 16 & 53,33 \\
\hline Sedang /Average & 11 & 36,67 & 12 & 40,00 \\
\hline Tinggi /High & 14 & 46,66 & 2 & 6,67 \\
\hline Jumlah/Total & 30 & 100.00 & 30 & 100 \\
\hline
\end{tabular}

Sumber : Data Primer Diolah, 2007/Source : Primary Data Processed, 2007.

Keterangan/Remarks:

Pendapatan Rendah/Low Income $\quad=<\operatorname{Rp~933,333~}$

Pendapatan Sedang/Average Income $=$ Rp 933,333-Rp 2.533.333

Pendapatan Tinggi/ High Income $\quad=>$ Rp 2.533.333

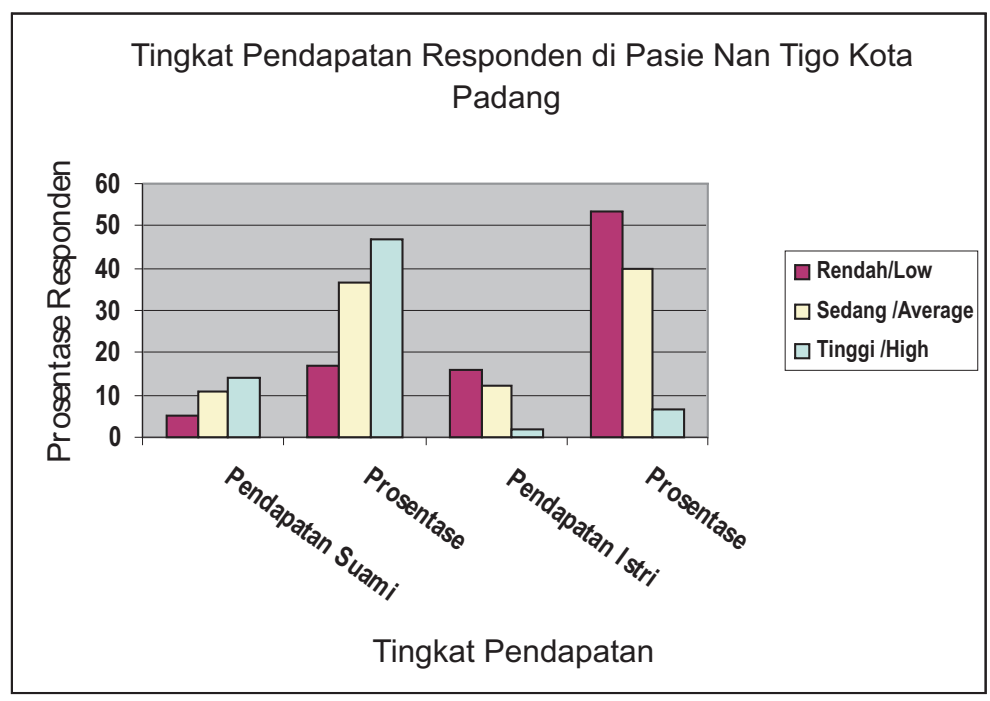

Gambar 1. Tingkat Pendapatan Responden di Pasie Nan Tigo Kota Padang. Picture 1. Income Level Distribution Respondent in Pasie Nan Tigo, Padang. 
Kelurahan Pasie Nan Tigo) dimana usahausaha pengolahan antara lain pengolah ikan tradisional, Abon ikan, Kerupuk Ikan, Rakit Maco, Rakit Kacang dan diluar bidang perikanan seperti kue katus, kue bulu. Para istri nelayan disini sering mengikuti pelatihanpelatihan keterampilan bermacam-macam pengolahan yang diadakan oleh Dinas Perikanan maupun perguruan tinggi (Universitas Andalas dan Universitas Bung Hatta). Sedangkan para suami (nelayan) didaerah ini banyak waktu luangnya tidak dimanfaatkan misalnya kalau musim paceklik (kebanyakan waktunya tidak melaut), bahkan ada beberapa orang melakukan hal-hal yang tidak bermanfaat (main judi), jadi di Kelurahan Pasie Nan Tigo terjadi ketimpangan jender dalam hal mencari nafkah.

\section{Profil Kegiatan}

Pola pekerjaan anggota rumahtangga nelayan tidak terlepas dari kultur dan kebiasan hidup di lingkungan mereka. Pola pekerjaan anggota rumahtangga umumnya dibedakan berdasarkan gender dan berlangsung dari generasi kegenerasi melalui proses sosialisasi.

Pola pekerjaan anggota rumahtangga dapat pula dipilah atau dibedakan dalam tiga kelompok yaitu pekerjaan reproduktif, produktif dan sosial. Pemilahan pola pekerjaan anggota rumahtangga tersebut bukan berarti terdapat pembatasan anggota rumahtangga baik laki-laki maupun perempuan pada masing-masing pola pekerjaan. Dalam kenyataannya keterlibatan laki-laki juga terdapat pada pekerjaan reproduktif yang dominan dilakukan perempuan. Demikian pula pekerjaan produktif yang dominan dikerjakan laki-laki, bahkan terkadang lebih didominasi oleh perempuan pada rumahtangga. Dengan demikian pemilahan wilayah kerja tersebut tidaklah merupakan suatu hal yang kaku, karena dengan sendirinya pemilahan wilayah kerja tersebut akan berubah secara dinamis seiring dengan kebutuhan hidup masyarakat.

Pada penelitian ini profil kegiatan ada 4(empat) antara lain kegiatan produktif, Domestik, Curahan waktu luang dan kebutuhan dasar anggota keluarga dan sosial. Aktivitas pekerjaan rumahtangga dimulai pada waktu keberangkatan laki-laki melaut. Meskipun waktu keberangkatan melaut pada dinihari atau tengah malam, perempuan tetap melakukan aktivitas untuk mempersiapkan makanan atau ransum yang akan dibawa kelaut. Apabila waktu berangkat melaut berkisar jam 01.00 WIB sampai jam 04.00 WIB biasanya perempuan masih menyempatkan untuk melanjutkan tidur.

Kegiatan produktif penangkapan ikan masih didominasi oleh laki-laki antara lain persiapan perbekalan melaut, penangkapan

Tabel 5. Curahan Waktu Terhadap Profil Kegiatan Responden di Desa Pasie Nan Tigo Kota Padang.

Table 5. Time Spent to Respondent Activity Profile To Respondent Action in the Pasie Nan Tigo

\begin{tabular}{clcc}
\hline \multirow{2}{*}{ No } & \multicolumn{1}{c}{ Profil Kegiatan / Activities Profile } & \multicolumn{2}{c}{ Curahan Waktu /Spent Time (n=30) } \\
\cline { 3 - 4 } & $\begin{array}{l}\text { Kegiatan produktif (jam/hari)/ Produktive } \\
\text { activities (hours/day) }\end{array}$ & 14,90 & Istri /Wife \\
2 & $\begin{array}{l}\text { Kegiatan domestik (jam/hari)/ Domestic } \\
\text { activities (hours/day) }\end{array}$ & 1,38 \\
3 & $\begin{array}{l}\text { Waktu luang dan kebutuhan dasar keluarga } \\
\text { (jam /hari)/ Spare time and family base }\end{array}$ & 7,04 & 10,71 \\
needed (hours/day) & $\begin{array}{l}\text { Aktivitas/kegiatan sosial (jam /minggu)/ } \\
\text { Social activities (hours/week) }\end{array}$ & 0,67 & 0,83 \\
\hline
\end{tabular}

Sumber : Data Primer Diolah, 2007/Source : Primary Data Processed, 2007. 
ikan, pembongkaran ikan, penjualan ikan, memperbaiki alat tangkap, memperbaiki kapal, membersihkan kapal/jaring dan memperbaiki mesin sedangkan istri nelayan selain melakukan pengolahan ikan juga kadang-kadang membantu membersihkan kapal/jaring.

Untuk kegiatan domestik dominan dilakukan oleh istri nelayan mulai dari mengambil air untuk kebutuhan sehari-hari, memasak, mencuci alat rumahtangga dan pakaian, menyeterika, belanja, membersihkan rumah, mengasuh anak, membantu anak dalam belajar dan nelayan (suami) membantu dalam kadang-kadang mengambil air, mengasuh anak dan membantu anak dalam belajar.

Curahan waktu luang dan kebutuhan dasar anggota keluarga termasuk waktu luang (hiburan dan istirahat). Sedangkan kebutuhan dasar (tidur, mandi dan makan) kegiatan waktunya hampir seimbang tetapi masih dominan dimanfaatkan oleh suami karena waktu luangnya lebih banyak dibanding istri nelayan.

Kegiatan sosial hampir seimbang antara suami dan istri termasuk antara lain pelatihan keterampilan, pelayanan kesehatan, pertemuan kelompok nelayan, kerja bakti, Arisan, Pengajian, Pesta laut, ngerumpi/ngobrol santai.

\section{Profil Akses dan Kontrol}

Akses adalah peluang yang bisa diperoleh laki-laki dan perempuan untuk memiliki atau menikmati sesuatu (pekerjaan, kegiatan, barang, jasa). Sementara kontrol adalah sejauhmana perempuan dan laki-laki mempunyai kekuasaan atau kemampuan dalam proses pengambilan keputusan dalam merencanakan, melakukan/memiliki atau menikmati sesuatu (Handayani dan Sugiarti, 2001). Laki-laki dan perempuan yang dapat mengakses sumberdaya tertentu belum tentu memiliki kontrol terhadap sumberdaya tersebut. Hal ini disebabkan karena akses seseorang ditentukan oleh orang lain, sementara kontrol mencirikan bahwa seseorang itu berkuasa atau tidak untuk menentukan sumberdaya yang diakses atau tidak diakses. Dengan demikian kontrol merupakan kekuasaan yang dimiliki sesorang terhadap sumberdaya yang dapat digunakan untuk berbagai hal sehingga benar-benar memberi manfaat.

\section{Tabel 6. Pengambilan Keputusan Dalam Aktifitas Domestik Responden Di Desa Pasie Nan Tigo Kota Padang.}

Table 6. Decision Making on Domestic Activities in the Pasie Nan Tigo Village, Padang.

\begin{tabular}{|c|c|c|c|c|}
\hline \multirow[b]{2}{*}{ No } & \multirow[b]{2}{*}{ Aktifitas Domestik/Domestic Activities } & \multicolumn{3}{|c|}{ n (\%) } \\
\hline & & $\begin{array}{l}\text { Istri / } \\
\text { Wife }\end{array}$ & $\begin{array}{c}\text { Suami + Istri/ } \\
\text { Husband+ } \\
\text { Wife }\end{array}$ & $\begin{array}{l}\text { Suami/ } \\
\text { Husband }\end{array}$ \\
\hline 1 & Penyediaan makanan/ Food preparation & $\begin{array}{r}30 \\
(100)\end{array}$ & 0 & 0 \\
\hline 2 & Pendidikan anak/ Children education & $\begin{array}{r}8 \\
(26,66)\end{array}$ & $\begin{array}{r}21 \\
(70)\end{array}$ & $\begin{array}{r}1 \\
(3,33)\end{array}$ \\
\hline 3 & Tabungan/Saving & $\begin{array}{r}10 \\
(66,66)\end{array}$ & $\begin{array}{r}18 \\
(60)\end{array}$ & $\begin{array}{r}2 \\
(6,66)\end{array}$ \\
\hline 4 & $\begin{array}{l}\text { Pengadaan peralatan rumah tangga/ } \\
\text { Household equipment supply }\end{array}$ & $\begin{array}{r}9 \\
(30,00)\end{array}$ & $\begin{array}{r}15 \\
(50,00)\end{array}$ & $\begin{array}{r}6 \\
(20,00)\end{array}$ \\
\hline 5 & Reproduksi/Reproduction & $\begin{array}{r}7 \\
(23,33)\end{array}$ & $\begin{array}{r}23 \\
(76,66)\end{array}$ & 0 \\
\hline
\end{tabular}

Sumber : Data Primer Diolah, 2007/Source : Primary Data Processed, 2007. 
Tabel 7. Pengambilan Keputusan dalam Aktifitas Produktif Responden di Desa Pasie Nan Tigo Kota Padang

Table 7. Decision Making on Productive Activities in the Pasie Nan Tigo Village, Padang .

\begin{tabular}{|c|c|c|c|c|}
\hline \multirow[b]{2}{*}{ No } & \multirow[b]{2}{*}{$\begin{array}{l}\text { Aktifitas Produktif/ } \\
\text { Productive Activities }\end{array}$} & \multicolumn{3}{|c|}{$\mathrm{N}(\%)$} \\
\hline & & $\begin{array}{l}\text { Dominasi } \\
\text { Istri/Wife } \\
\text { Domination }\end{array}$ & $\begin{array}{l}\text { Suami + Istri/ } \\
\text { Husband+ } \\
\text { Wife }\end{array}$ & $\begin{array}{l}\text { Dominasi } \\
\text { Suami/ } \\
\text { Husband } \\
\text { Domination }\end{array}$ \\
\hline 1 & $\begin{array}{l}\text { Investasi/ Modal usaha } \\
\text { perikanan/Investment on } \\
\text { fisheries business }\end{array}$ & $\begin{array}{r}13 \\
(43,33)\end{array}$ & $\begin{array}{r}14 \\
(46,66)\end{array}$ & $\begin{array}{r}3 \\
(10,00)\end{array}$ \\
\hline 2 & $\begin{array}{l}\text { Pengelolaan usaha } \\
\text { perikanan/Fisheries business } \\
\text { management }\end{array}$ & $\begin{array}{r}2 \\
(6,66)\end{array}$ & $\begin{array}{r}11 \\
(36,66)\end{array}$ & $\begin{array}{r}17 \\
(56,66)\end{array}$ \\
\hline 3 & $\begin{array}{l}\text { Pengelolaan usaha } \\
\text { pengolahan/Processing business } \\
\text { management }\end{array}$ & $\begin{array}{r}19 \\
(63,33)\end{array}$ & $\begin{array}{r}11 \\
(36,66)\end{array}$ & 0 \\
\hline 4 & $\begin{array}{l}\text { Pengelolaan usaha non } \\
\text { perikanan/Non fisheries business } \\
\text { management }\end{array}$ & $\begin{array}{r}2 \\
(6,66)\end{array}$ & $\begin{array}{r}21 \\
(70,00)\end{array}$ & $\begin{array}{r}7 \\
(23,33)\end{array}$ \\
\hline 5 & $\begin{array}{l}\text { Sosial kemasyarakatan/ Social } \\
\text { community }\end{array}$ & $\begin{array}{r}5 \\
(16,66)\end{array}$ & $\begin{array}{r}20 \\
(66,66)\end{array}$ & $\begin{array}{r}5 \\
(16,66)\end{array}$ \\
\hline
\end{tabular}

Sumber : Data Primer Diolah, 2007/Source : Primary Data Processed, 2007.

Pada kegiatan penelitian terlihat akses dan kontrol pada kegiatan domestik didominasi istri bukan berarti suami tidak ada andil dalam pengambilan keputusan, begitupun pada kegiatan produktif akses kontrol hampir seimbang dan kalau dilihat kegiatan keseluruhan terjadi bias gender yang merugikan istri nelayan.

\section{Persepsi tentang Gender dalam Keluarga Nelayan}

Pada Tabel 8 responden paling banyak memilih alternatif pilihan ke 4 (empat) karena pada umumnya mereka berpendapat bahwa perbedaan jenis kelamin tidak harus dipertentangkan dalam menghidupi keluarga, tetapi justru bersifat saling mendukung dan melengkapi.

Pernyataan tersebut didukung oleh kenyataan di lapangan menunjukkan bahwa dari jumlah 30 orang responden istri nelayan sebahagian besar (26 orang atau $86,66 \%$ ) ikut membantu suami dalam mencari nafkah keluarga, namun demikian istri nelayan tidak melupakan tugas utamanya mengurus rumah tangga (urusan domestik), jadi wanita di desa ini mempunyai tugas ganda, disamping mengurus rumah tangga juga juga mengurus urusan diluar rumah tangga (tambahan pendapatan). Sejalan dengan hasil penelitian Kusnadi (2001) menyebutkan bahwa dalam masyarakat nelayan terdapat pola pembagian kerja secara seksual yang sangat kuat pengaruhnya secara kultural yaitu "laut adalah wilayah laki-laki, sedangkan darat adalah wilayah perempuan". Karena alasan ekonomi yaitu penghasilan suami tidak mencukupi kebutuhan keluarga maka umum terjadi dalam masyarakat nelayan istri harus bekerja untuk ikut menambah penghasilan keluarga. Masyarakat nelayan (baik nelayan maupun istrinya) di Desa ini memiliki pemikiran yang cukup terbuka mengenai peranan antara suami dan istri dalam keluarga.

\section{Tugas Berdasarkan Gender dalam Keluarga Nelayan \\ Pada Tabel 9 berikut ini yang paling}


Tabel 8.Sebaran Contoh Berdasarkan Alternatif Pilihan Persepsi Tentang Gender di Desa Pasie Nan Tigo Kota Padang.

Table 8. Sample Distribution of Alternative Perception Option Regarding With Gender in The Pasie Nan Tigo Village, Padang .

\begin{tabular}{|c|c|c|c|}
\hline No & Alternatif Pilihan/Alternative Selection & $\begin{array}{l}\text { Suami/ } \\
\text { Husband }\end{array}$ & $\begin{array}{l}\text { Istri/ } \\
\text { Wife }\end{array}$ \\
\hline 1 & $\begin{array}{l}\text { Istri adalah mahluk yang lebih lemah secara fisik } \\
\text { dan mental dari suami sehingga wajar berada } \\
\text { dalam posisi sosial yang lebih rendah dalam } \\
\text { keluarga./ Wife is physically and mentally weaker } \\
\text { than husband and deserved to has lower social } \\
\text { position in family }\end{array}$ & $\begin{array}{r}5 \\
(16,66 \%)\end{array}$ & $\begin{array}{r}4 \\
(13,33 \%)\end{array}$ \\
\hline 2 & $\begin{array}{l}\text { Istri tidak lebih lemah dari suami sehingga wajar bila } \\
\text { berkedudukan sejajar dalam mengatur keluarga./ } \\
\text { Wife is not weaker than husband and has equal } \\
\text { position in family management }\end{array}$ & $\begin{array}{r}3 \\
(10,00 \%)\end{array}$ & $\begin{array}{r}6 \\
(20,00 \%)\end{array}$ \\
\hline 3 & $\begin{array}{l}\text { Istri mampu memberi kontribusi lebih dari suami } \\
\text { dalam menghidupi keluarga dan layak untuk } \\
\text { mengelola keluarga / wife is capable contribute } \\
\text { more than husband and deserved to manage the } \\
\text { family }\end{array}$ & $\begin{array}{r}5 \\
(16,66 \%)\end{array}$ & $\begin{array}{r}9 \\
(30,00 \%)\end{array}$ \\
\hline \multirow[t]{2}{*}{4} & $\begin{array}{l}\text { Istri dan suami menyadari bahwa perbedaan jenis } \\
\text { kelamin tidak harus dipertentangkan dalam } \\
\text { menghidupi keluarga, tetapi justru bersifat saling } \\
\text { mendukung dan melengkapi/ wife and husband } \\
\text { realize that gender is not a subject of confrontation } \\
\text { but it can be support each other }\end{array}$ & $\begin{array}{r}17 \\
(56,66 \%)\end{array}$ & $\begin{array}{r}11 \\
(36,66 \%)\end{array}$ \\
\hline & Jumlah/Total & $\begin{array}{r}30 \\
(100 \%)\end{array}$ & $\begin{array}{r}30 \\
(100 \%)\end{array}$ \\
\hline
\end{tabular}

Sumber : Data Primer Diolah, 2007/Source : Primary Data Processed, 2007.

banyak dipilih oleh responden adalah alternatif pilihan ke dua yaitu tugas utama istri adalah mengurus rumahtangga tetapi boleh membantu tugas suami dalam mencari nafkah keluarga sedangkan tanggungjawab mencari nafkah tetap tugas suami yaitu 40,00 persen (12 orang) dan 33,33 persen (29 orang) untuk istri.

Walaupun tugas utama suami mencari nafkah akan tetapi peranan istri dalam membantu suami di desa ini dalam hal membantu pendapatan keluarga tidak kecil, jika dilihat dari kesetaraan gender (data primer diolah) banyak merugikan kaum wanita (istri nelayan) namun demikian karena faktor kultural kondisi ini tidak menjadi masalah. Pernyataan tersebut sesuai dengan hasil penelitian Saruan (2000) antara lain mengatakan bahwa pada masyarakat nelayan diberbagai wilayah ditemukan kaum perempuan yang dikenal sebagai pekerja ulet dalam berbagai aktivitas untuk menunjang perekonomian keluarga, khususnya aktivitas yang langsung berhubungan dengan persiapan produksi, pemrosesan dan pemasaran hasil, sedangkan laki-laki bekerja dalam bidang operasi penangkapan.

\section{KESIMPULAN DAN IMPLIKASI KEBIJAKAN}

1. Alokasi curahan waktu suami terhadap aktivitas produktif lebih besar dibanding istri yaitu sebesar 11,16 jam/hari, sedangkan alokasi untuk aktivitas produktif istri nelayan sebesar 8,11 jam/hari. Untuk aktivitas domestik alokasi 


\section{Tabel 9. Sebaran Contoh Berdasarkan Alternatif Pilihan Tugas Berdasarkan Gender di Kelurahan Pasie Nan Tigo, Kota Padang.}

Table 9. Sample Distribution of Alternative Role Gender Based on in The Pasie Nan Tigo Village Padang .

\begin{tabular}{|c|c|c|c|}
\hline No & Alternatif Pilihan /Alternative Selection & $\begin{array}{l}\text { Suami/ } \\
\text { Husband }\end{array}$ & Istri/Wife \\
\hline 1. & $\begin{array}{l}\text { Tugas istri adalah mengurus rumah tangga saja, } \\
\text { sedangkan tugas suami adalah mencari nafkah saja } \\
\text { bagi keluarga. / wife's duty is to manage the family } \\
\text { and husband's duty is earning money for family }\end{array}$ & $\begin{array}{r}7 \\
(23,33 \%)\end{array}$ & $\begin{array}{r}8 \\
(26,66 \%)\end{array}$ \\
\hline 2. & $\begin{array}{l}\text { Tugas utama istri adalah mengurus rumah tangga, } \\
\text { tetapi boleh m embantu tugas suami dalam mencari } \\
\text { nafkah keluarga sedangkan tanggung jawab } \\
\text { mencari nafkah utama tetap tugas suami. / Main } \\
\text { duty of wife to manage the family but she is allowed } \\
\text { to help husband to earn money. }\end{array}$ & $\begin{array}{r}12 \\
(40,00 \%)\end{array}$ & $\begin{array}{r}10 \\
(33,33 \%)\end{array}$ \\
\hline 3. & $\begin{array}{l}\text { Tugas suami tidak hanya mencari nafkah bagi } \\
\text { keluarga, tetapi juga harus mau membantu/berbagi } \\
\text { tugas dengan istri dalam mengurus rumahtangga. / } \\
\text { Main duty of husband is not only to earn money for } \\
\text { family, but also to share the family management } \\
\text { with wife. }\end{array}$ & $\begin{array}{r}5 \\
(16,66 \%)\end{array}$ & $\begin{array}{r}7 \\
(23,33 \%)\end{array}$ \\
\hline 4. & $\begin{array}{l}\text { Tugas istri mengurus rumah tangga boleh } \\
\text { digantikan orang lain bila ia mampu mencari nafkah } \\
\text { untuk keluarga dalam jumlah yang besar. / Wife's } \\
\text { duty in family management can be substituted by } \\
\text { other person as long as she is able to earn much } \\
\text { money. }\end{array}$ & $\begin{array}{r}4 \\
(13,33 \%)\end{array}$ & $\begin{array}{r}3 \\
(10,00 \%)\end{array}$ \\
\hline \multirow[t]{2}{*}{5.} & $\begin{array}{l}\text { Tugas utama istri mengurus rumah tangga dan } \\
\text { tugas utama suami mencari nafkah bagi keluarga } \\
\text { boleh bertukar apabila secara ekonomi memang } \\
\text { menguntungkan./ Wife's duty is to manage the } \\
\text { family and husband's duty is to earn money but they } \\
\text { can exchange the duty as long as beneficial } \\
\text { economically. }\end{array}$ & $\begin{array}{r}2 \\
(6,66 \%)\end{array}$ & $\begin{array}{r}2 \\
(6,66 \%)\end{array}$ \\
\hline & Jumlah/Total & $\begin{array}{r}30 \\
(100,00 \%)\end{array}$ & $\begin{array}{r}30 \\
(100,00 \%)\end{array}$ \\
\hline
\end{tabular}

Sumber : Data Primer Diolah, 2007/Source : Primary Data Processed, 2007.

waktu suami rata-rata hanya 3,20 jam/hari, sedangkan alokasi waktu istri untuk kegiatan domestik 9,49 jam/hari. Untuk alokasi waktu luang suami 8,02 $\mathrm{jam} / \mathrm{hari}$ dan alokasi waktu luang istri lebih kecil 6,2 jam/hari, sedangkan alokasi curahan waktu untuk aktivitas sosial suami rata-rata 2,93 jam/hari dan alokasi curahan waktu istri untuk aktivitas sosial sebesar 2,00 jam/hari.
2. Masih adanya ketimpangan jender yang mewarnai pola kerja masyarakat nelayan setempat yakni adanya beban kerja, dimana istri memiliki peran ganda yaitu sebagai penanggung jawab dalam urusan rumah tangga dan juga membantu suami sebagai pencari nafkah.

3. Persepsi gender yang paling banyak dianut oleh suami dan istri dalam keluarga nelayan pada masyarakat tersebut adalah 
istri dan suami menyadari bahwa perbedaan jenis kelamin tidak harus dipertentangkan dalam menghidupi keluarga, tetapi justru bersifat saling mendukung dan melengkapi. Sedangkan tugas berdasarkan jender yang paling dianut baik oleh suami dan istri dalam keluarga nelayan pada masyarakat tersebut adalah tugas utama istri adalah mengurus rumah tangga tetapi boleh membantu tugas suami dalam mencari nafkah keluarga sedangkan tanggung jawab mencari nafkah utama tetap tugas suami.

\section{DAFTAR PUSTAKA}

Badan Pusat Statistik, 2003. Data Potensi Desa di Indonesia, Jakarta.

Balai Besar Riset Sosial Ekonomi Kelautan dan Perikanan. 2005. Indikator Kinerja Pembangunan Sektor Kelautan dan Perikanan: Executive Summary. BBRSEKP. Jakarta.

Departemen Kelautan dan Perikanan. 2006. Bahan Rapat Kerja Menteri Kelautan dan Perikanan dengan Komisi IV DPR RI tanggal 27 Pebruari 2006. Departemen Kelautan dan Perikanan. Jakarta.

Departemen Kelautan dan Perikanan. 2006.

Rencana Strategis Pembangunan Kelautan dan Perikanan Tahun 2005 2009. Jakarta. Departemen Kelautan dan Perikanan.

Dewantoro et al, 2005. Peranan Wanita Tani Nelayan dalam Masyarakat Nelayan Perairan umum Danau Pangembung,
Kabupaten Kapuas Hulu, Jurnal Penelitian Perikanan Indonesia Edisi Sosial Ekonomi, Badan Riset Kelautan dan Perikanan, DKP, Jakarta.

Handayani, T. dan Sugiarti, 2002. Konsep dan Teknik Penelitian Gender. Penerbit Universitas Muhammadiyah Malang. Malang.

Kusnadi, 2001. Pangamba. Kaum Perempuan Fenomenal, Pelopor dan Penggerak Perekonomian Masyarakat Nelayan. Humaniora Utama Press, Bandung.

Nasution, Z., Sastrawidjaja, Hartono, T., Mursidin, Priyatna, F,N., Pranadji, T., Bayu Aji, G., Koeshendrajana, S., dan Suherman, M., 2004. Kondisi Sosio Antropologi Masyarakat Nelayan. Laporan Teknis Kegiatan Riset Tahun 2004. PRPPSEKP. BRKP. Jakarta (unpublished).

Purnamawati dan Lumangkun, A. 2000. Lokakarya Sosialisasi dan Inkorporasi Saga pada Penelitian dan Pengkajian Teknologi Pertanian. Pontianak 18 - 23 September 2000.

Saruan, 2000. Studi Gender Pada Rumah Tangga Nelayan dalam Pengelolaan Sumberdaya pesisir dan Lautan. Bogor. Tesis Program Pascasarjana. IPB. Bogor. (unpublished).

Syufri, A., 2005. Prmberdayaan Nelayan Tradiasional: Kasus Peyuluhan di Sepanjang Pantai Kota Padang, Sekolah Pasca Sarjana, IPB, Bogor 